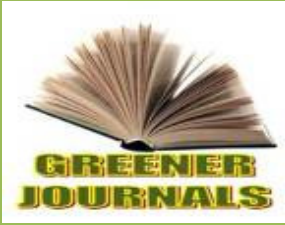

\title{
The Effect of the Application of Different Rates of Herbicides on the Growth and Yield Component of Zea mays L
}

\author{
${ }^{* 1}$ Mrs. Joyce Chinyere Best-Ordinioha, \\ ${ }^{2}$ Prof. Anthony E. Ataga, ${ }^{3}$ Dr. Edache B. Ochekwu
}

\author{
1Doctoral Student, Department of Plant Science and Biotechnology,Faculty of Sciences, \\ University of Port Harcourt, Port Harcourt, Rivers State. \\ 2Professor, Department of Plant Science and Biotechnology, Faculty of Sciences, University of \\ Port Harcourt, Port Harcourt, Rivers State. \\ ${ }^{3}$ Senior Lecturer, Department of Plant Science and Biotechnology, Faculty of Sciences, University \\ of Port Harcourt, Port Harcourt, Rivers State
}

Article No.: 110716202

DOI: 10.15580/GJAS.2017.1.110716202

Submitted: 07/11/2016

Accepted: 14/11/2016

Published: 01/02/2017

*Corresponding Author

Joyce Chinyere Best-Ordinioha

E-mail: pphconsult@gmail.com

Keywords:

Herbicides, weed control, germination count, yield, growth parameter, maize, Nigeria
Background: Weeds are responsible for low crop yield, and responsible for the large gap between the potential and actual yield per hectare. The traditional manual method of weed control in Nigeria has become very difficult and expensive, because of the cost of hiring labor, particularly during the peak cropping period, due to increasing rural-urban migration. This has encouraged the use of herbicides in weed control, even by untrained illiterate farmers, hence the need to assess the effects of the use on yield. This study assessed the effects of the application of different concentration of herbicides on the growth and yield of maize, cultivated in succeeding years.

Materials and methods: The study was carried out in a plot of land at the University of Port-Harcourt in 2013 and 2014, using a randomized complete block design with three replicates, and plot size of $2 \mathrm{~m} \mathrm{x}$ $2 \mathrm{~m}$. Glyphosate was used to prepare the experimental plots, while different application doses of primextra dual gold (atrazine and metolachlor) were applied to the plots, after planting the maize. The control plot was not treated with the herbicides. The growth and yield parameters of the maize planted in the plots were assessed through the physio-chemical characteristics of the soil, the germination count, leaf count, height of maize plant, and the yield of maize at harvest.

Results: The application of the herbicides resulted in improvements in the growth and yield parameters of the maize. The parameters in the plots in which the herbicides had been applied at or below the manufacturer's recommended dose (2.11ai/ha) were comparable to those of the control; and then significantly decreased in the plots in which the herbicides were applied in overdose. The parameters were also higher in the first phase of the study, compared to the second phase that took place one year later in the same plots. There was also a reduction in the organic matter and exchangeable minerals content of the soil in the second phase of the study.

Conclusion: The application of herbicides for weed control, up to their recommended doses resulted in a one-off improvement in the growth and yield parameters of the cultivated maize crop. Efforts are therefore needed to properly educate farmers. 


\subsection{BACKGROUND OF STUDY}

Household food security is a big problem in Nigeria. This is in spite of the fact that Nigeria has a large expanse of arable agricultural land (Eme et al, 2014; Ojo and Adebayo, 2012). Studies indicate that the cultivation of Nigeria's arable land are hampered by the drudgery of farming activities, especially as most of the farming are carried out by subsistent farmers, using manual agricultural tools (Ojo and Adebayo, 2012). A substantial part of the drudgery is linked to weed control, especially in the hot, humid environment of southern Nigeria that is known to encourage rapid growth of weed (lyagba, 2013; Agahiu et al 2012; Agahiu et al 2011).

Studies indicate that weeds are responsible for low crop yield, and that the cost of weed control is among the most expensive items in crop production in Nigeria lyagba, 2013; Agahiu et al, 2012). Studies carried out by Khan et al (2003) indicate that weed is responsible for the large gap between the potential and actual yield per hectare of the maize crop; while Adigun (2001) showed that excessive growth of weeds in maize field results in between $66 \%$ and $80 \%$ reduction in crop yield.

Weeds have such significant effects on crop yield, because they interfere with the normal growth of crops, through competition for nutrients, moisture, space, sunlight, carbon dioxide and water (van Heemst, 1985). Weeds also serve as host for various pests and diseases that produce chemical substances that can be allergens or toxins to crop plants. There are also indications that weeds limit the choice of crop rotation sequences and cultural practices. Other studies have shown that weeds contaminate the crop and the harvest, apart from making it more difficult to harvest the crop (van Heemst, 1985).

Minimizing the losses caused by weeds in crop production is therefore very important, particularly during the critical growth stage (pre and early post emergence stage) in other to obtain a good harvest yield (Hamid et al. 2000 and Agahiu et al 2011). Weed control can be carried out using several control measures including biological, chemical and mechanical methods. The mechanical method of weed control is however the most commonly used method in Nigeria, and involve the use of manual implements such as hoes and cutlass (Agahiu et al 2012). This method is however very laborious, time consuming and very expensive, especially in the hot, humid environment of southern Nigeria, where the growth of weed is very rapid, and the increasing ruralurban migration has made it very difficult and expensive to hire labor, particularly during the peak cropping period (Agahiu et al 2012).

The use of the herbicides in weed control has been found to be quicker, more cost-effective and involves less drudgery, and is therefore recommended by many researchers (Toloraya et al 2001; Khan and Noor-ul-Haq; 2004; Ahmed et al., 2008). The use of herbicide in weed control has grown significantly in Nigeria in recent years (lyagba, 2013; Agahiu et al 2012; Agahiu et al 2011), linked to the ease of application, and the effectiveness of the herbicide in controlling the common weeds in Nigeria (Agahiu et al 2012; Agahiu et al 2011; Tijani, 2006).

Studies indicate that the use of herbicides in weed control can increase the yield of such important staple crops such maize and cassava. (Hawaldar \& Agasimani, 2012; Enyong et al, 2013; Agahiu et al, 2011). There is however the need to evaluate the yield potential of the various doses of the herbicides, especially as the herbicides are mostly used by untrained, illiterate farmers, with little knowledge of the proper dosing of the herbicides. There is also a need to assess the effects of the use of the herbicides on the yield of subsequent use of the farm, especially as shortage of agricultural lands in Nigeria is making it difficult for farmers to practice the traditional shifting cultivation.

This study was therefore designed to evaluate the effects of the application of different concentration of herbicides on the growth and yield of maize, cultivated in succeeding years. The study was carried out in maize (Zea mays $L$ ), because it is one of the crops in which the herbicides are commonly used to cultivate in Nigeria. The fact that maize is a short duration crop also makes it ideal for a study of this type.

\section{MATERIALS AND METHODS}

\subsection{EXPERIMENTAL SITE AND LOCATION}

The field studies were carried out in a plot of land at the University of Port-Harcourt during the 2013 and 2014 farming seasons, with the experiment laid out in a randomized complete block design with three replicates, and plot size of $2 \mathrm{~m} \times 2 \mathrm{~m}$. The experimental farm is well drained plot of land, with sandy loam soil, located at a latitude of $4.9027^{\circ} \mathrm{N}$, and a longitude of $6.9205^{\circ} \mathrm{E}$. It is in the rainforest ecological zone of the Niger delta region, and like most other communities in southern Nigeria has two seasons, the rainy season and the dry season, with an average annual rainfall of about 3,000 $\mathrm{mm}(118.1 \mathrm{in})$.

\subsection{Land preparation and application of herbicides}

The experimental site was fallowed for two years, and was prepared for the experiment by the application of "Round-Up", a proprietary glyphosate herbicide, bought from the Port Harcourt office of the Rivers State Agricultural Development Programme (ADP). This non- 
till methods was adopted for the study, because it has been shown to reduce leaching and erosion (Ding et al, 2002), which is vital in containing the experimental herbicides within the experimental plots.

Glyphosate [N-(phosphonomethyl) glycine] is the most widely used herbicide in the world, preferred for its low toxicity to mammals, and its low environmental impact (Franz et al, 1997). It was used in preparing the experimental plot for the study, not only for its low toxicity to mammals and the environment, but also because of its broad spectrum, non-selective weed killing capacity, and its proven effectiveness in non-till agriculture (Franz et al, 1997). The glyphosate was applied to the experimental plot at the manufacturer's recommended rate; and resulted in the complete burning off of the weeds. The experimental site was then left for two weeks, to allow the burnt grasses to completely dry, before the maize seeds are planted in rows.

The maize variety used for the study, the swan1-yellow was obtained from the Green River Project of the Nigerian Agip Oil Company, and is widely cultivated in the farming communities of the Niger delta region. The seeds were sown using the recommended seed rate of $25 \mathrm{~kg} /$ hectare, at a planting distance of $75 \mathrm{~cm}$ between the rows, while an intra-row spacing distance of $25 \mathrm{~cm}$ was maintained on flat. Extra plants were thinned out at the early growth stage, to maintain one plant per hole after two weeks of planting.

Primextra dual gold, a proprietary herbicide containing $290 \mathrm{~g} / \mathrm{l}$ of metolachlor and $370 \mathrm{~g} / \mathrm{l}$ of atrazine, manufactured by Syngenta Nigeria Limited, and purchased from a local dealer in Port Harcourt was then applied to the experimental plot, immediately after planting the maize. Atrazine \{2-chloro-4-(ethylamino)-6isopropylamino-1,3-5-triazine $\}$ is one of the most widely used 5-triazine herbicide, used either singly, or in combination with other herbicides, as a pre-emergence herbicide in the control of broadleaf and grassy weeds (Munier-Lamy et al 2002; Hamid et al, 2011); while metolachlor [2-chloro-N-(ethy-6-methy(phenyl)-N-(2methoxyl-1-methylethyl acetamide] on the other hand is commonly used in combination with other herbicides, because it is a very selective herbicide, renowned for its activity against grassy weeds (Cao et al, 2008).

The Primextra dual gold was applied to the experimental plots at five different rates, corresponding to a quarter of the recommended dose, half of the recommended dose, the recommended dose, 1.5 times the recommended dose, and twice the recommended. The information label of the Primextra dual gold used for the study showed that the product contains $290 \mathrm{~g} / \mathrm{l}$ of metolachlor and $370 \mathrm{~g} / \mathrm{l}$ of atrazine, with a recommended dose for maize farm of 3.2 liters/hectare, which is equivalent to $2.11 \mathrm{~kg}$ ai/ha. Therefore, the herbicide was applied at $0.59 \mathrm{~kg}$ ai/ha, $1.06 \mathrm{~kg}$ ai/ha, $2.11 \mathrm{~kg}$ ai/ha, $3.17 \mathrm{~kg} \mathrm{ai} / \mathrm{ha}$ and $4.22 \mathrm{~kg}$ ai/ha to correspond to a quarter of the recommended dose, half of the recommended dose, the recommended dose, 1.5 times the recommended dose, and 2 times the recommended dose.
The control plot did not receive any herbicide application, before and after the maize seeds were planted. The plot was manually cleared with using the weeding hand hoe.

\subsection{The evaluation of the yield and growth parameters of the planted maize}

Data relevant in assessing the effects of the herbicides on the growth and yield of the maize crop include the physio-chemical characteristics of the soil, the germination count, the leaf count, the height of maize plant, and the yield of maize at harvest. These data were collected one week after planting the maize seeds, on the germination of the seeds (1WAP), and then four weeks (4WAP) and 12 weeks (12WAP) after.

The soil samples were collected diagonally from the experimental plots, at the beginning of each of the two phases of the study, before the preparation of the plots for the experiments, and at two different depths of $0-15 \mathrm{~cm}$ and $15-30 \mathrm{~cm}$. The germination count was taken one week after the maize were planted, to determine the number that germinated in each of the experimental plots, with the enumeration carried out according to the rows the maize was planted. The heights and the leaves of the maize were assessed at 4 and 12 weeks after planting (4WAP and 12WAP). This was carried out by the random selection of three of the maize plants, from two rows in each of the replicates, in all the experimental plots. The heights of the maize were measured from the surface of the soil to the growing tip of the main shoots, using a meter rule; while the yield of the maize planted in each of the experimental plots was determined by harvesting and weighing the cobs of three randomly selected maize plants, in two rows of each of the experimental plots. The mean weight of all the cobs harvested from the three maize plants is then calculated, and corrected to yield per hectare, to determine the yield of each of the experimental plots.

\subsection{Data Analysis}

The data collected during the study were put in a database, and then analyzed using SPSS and Microsoft Excel, after checking for consistency and completeness. Summary measures were calculated per hectare, for each outcome of interest, while the test of significance was conducted using the relevant statistical test, at 95\% confidence interval, with P-value of 0.05 or less considered statistically significant.

\section{RESULTS}

The physio-chemical characteristics of the soil of the experimental plots are presented Table 1. The soils are sandy loam in texture, very acidic and have a good content of organic matter. The electrical conductivity of the soil, at both depths, in the first phase were higher 
than the conductivity in the second phase of the study . The soil in the first phase of the study was also more acidic, contained more organic matter, more silt, and more exchangeable minerals than the soil at the second phase of the study.

The mean germination counts of the maize seeds sown in the experimental plots one week after planting are shown in Table 2. The mean germination counts in treated in first phase of $35,288.8$ plants/hectare is significantly higher than the count of $28,600.4$ plants/hectare in the second phase of the study (p-value < 0.01). In each phase of the study, the germination count in the treated plots were comparable to the control, up to the manufacturer recommended dose (2.11ai/ha); and then significantly decreased in the plots in which the herbicides were applied at above the manufacturer recommended dose. The results showed that the application of different concentrations of the herbicides had statistically significant effects on the germination count of the sown maize seeds ( $p$-value < 0.01).

The growth parameters of the maize sown in the experimental plots are shown in Table 3 below. The growth parameters of the maize sown in first phase of the study were significantly higher than those of the second phase of the study ( $p$-value $<0.05)$. The mean height and the mean leaf count of the maize sown in the first phase of the study was $75.94 \mathrm{~cm}$ and 7.31 respectively, compared to $60.50 \mathrm{~cm}$ and 4.97 in the second phase of the study.

Also in each phase of the experiment, the growth parameters of the maize sown in the plots in which the herbicides had been applied at or below the manufacturer's recommended dose (2.11ai/ha) were comparable to those of the control; and then significantly decreased in the plots in which the herbicides were applied in overdose.

The yield parameters of the maize planted in the experimental plots are presented in Table 4. The number and weight of the maize cobs harvested from the maize planted in the treated plot in first phase of the study were significantly higher than those of the second phase of the study. A total of $28,518.67$ maize cobs/hectare that weighed $3,677.6 \mathrm{~g}$ were harvested from the maize planted in the treated plots that had an average stover weight of $3,584.67 \mathrm{~g}$, in the first phase of the study, compared to the $17,708.5 \mathrm{cobs} /$ hectare that weighed $2128 \mathrm{~g}$ that were harvested from maize plants with a mean stover weight of $1,426.83$ in the second phase of the study.

Like the growth parameters, the yield parameters of the maize sown in the plots in which the herbicides had been applied at or below the manufacturer's recommended dose (2.11ai/ha) were comparable to those of the control; and then significantly decreased in the plots in which the herbicides were applied in overdose.

\section{DISCUSSION}

The study showed that the use of different doses of the herbicides, up to the recommended dose, positively affected the growth and yield of the maize, while the use of the herbicides in overdose adversely affected the parameters.

The germination counts in the treated plots are comparable to the control, up to the manufacturer recommended dose of the herbicide, and then decreased after the recommended dose is exceeded. The germination count in this study was highest in the recommended application dose of 2.11 ai/ha $(43,889)$, but comparable to the germination count of $41,667 /$ hectare recorded in the control plot, but significantly higher than the 23,333 /hectare recorded in the experimental plot in which twice the recommended dose was applied. This finding is however different from the study that was carried out with wheat that found that the germination count decreased steadily with increasing dose of the herbicide (Yazdanpak et al, 2014). The finding of this study can however be explained by several reasons including the fact that several varieties of maize, including the variety used for this study have been found to be resistant to the toxic effects of glyphosate, the herbicide used to prepare the treated plots. (Racchi et al, 1995; Sergiev et al, 2006). Racchi et al (1995) had found that several species of maize have physiological processes that make them resistant to glyphosate, while Sergiev et al (2006) had noted that the maize plant is able to protect itself against the toxicity of glyphosate through the use of phenylurea cytokinin 4PU30 . The marked decrease in germination count noted in the experimental plots in which overdose of the herbicides were applied can be explained by the fact that the atrazine and metolachlor, that were used as postemergent herbicides in the plots are known to be particularly toxic in overdose, and therefore have the capacity to adversely affect the germination of the maize (Yazdanpak et al, 2014).

The study showed that the application of the herbicides at or below the recommended dose had positive effects on the growth and yield of the maize, measured in terms of leaf count, height and stover weight of the maize planted in the plots, and the number and weight of the harvested cobs. In the first phase of the experiment, the mean stand at four weeks after planting the maize was highest in the experimental plot in which the recommended dose of the herbicide had been applied $(95.17 \mathrm{~cm})$, which is higher than the $79.72 \mathrm{~cm}$ of the control plot and the $74.78 \mathrm{~cm}$ in the plot in which a quarter of the recommended dose of the herbicide had been applied; but significantly higher than the mean height of $55.83 \mathrm{~cm}$ recorded in the experimental plot in which twice the recommended dose of the herbicide had been applied. This trend was also noted with the leaf count and stover weight of the sown maize, and the number and weight of the harvested cobs; and consistent with the findings of other studies 
carried out in maize, cassava and other staple crops (Hawaldar \& Agasimani, 2012; Enyong et al, 2013; Agahiu et al, 2011). Enyong et al (2013) in addition showed that the application of primextra, the proprietary herbicide combination of atrazine and metolachlor had the best positive effects on the crop, when the herbicide was applied in the recommended dose, higher than when the herbicide was applied below and above the recommended dose. This is also consistent with the finding of this study, and can be attributed to the direct toxicity of the overdose of atrazine and metolachlor (Yazdanpak et al, 2014).

This study however showed that the use of the post-emergent herbicides below the recommended dose had better positive effects than the overdose of the herbicides. The mean field cob weight of the maize harvested from the experimental plots in which subrecommended doses $(0.25$ and 0.5 of recommended dose) of the herbicides had been applied in the first phase of the study was $4271.5 \mathrm{~g}$, compared to $2644.5 \mathrm{~g}$ of the overdose plot (1.5x and $2 x$ of recommended dose). This can be attributed to the fertility boosting effects of glyphosate; (Neumann et al., 2006; Liu et al., 1991); as well as direct toxicity of the overdose of atrazine and metolachlor (Yazdanpak et al, 2014). This also accentuates the need to promote the use of the herbicides by subsistent farmers, who can still increase the yield of their crops, even with the use of subrecommended doses of the herbicides. This is especially as studies have indicated that such use of herbicides results in higher yield, compared to the traditional manual method of weed control (Enyong et al, 2013; Agahiu et al, 2011).

The study also showed that the growth and yield parameters were higher in the first phase of the study, compared to the second phase that was carried out one year later, in the same experimental plots. The germination count, mean height of the maize 4WAP, number and weight of cobs harvested from the treated plots were 35, 288.8 plants/hectare, $75.19 \mathrm{~cm}, 26,666.8$ cobs /hectare and 3, 682.8g respectively in the first phase of the study, which are higher than the 28,600.4 plants/hectare, $59.5 \mathrm{~cm}, 15,916.8$ cobs/hectare and 1 , $985.2 \mathrm{~g}$ recorded in the second phase. This can be attributed to the lingering effects of the herbicides in the experimental plots (Myers et al, 2016), and the physiochemical changes caused to the soil by the use of the herbicides (Ayansina and Oso, 2006; Liu et al., 1991; Sprankle, et al 1975; Krzysko-Lupicka et al., 1997). Studies conducted by Myers et al (2016) showed that herbicides persist in the soil longer than previously reported, and so the effects of the herbicides applied during the first phase of the study can easily extend to the second phase of the study.

Also there were noticeable changes in the physio-chemical properties of the soil. There was a significant decrease in the organic matter and phosphorus content of the soil in the second phase of the study. The organic matter content of soil decreased from $3.2 \%$ at the beginning of the first phase of the study to $2.15 \%$ at the beginning of the second phase of the study, while the phosphorus content decreased from $48 \mathrm{ppm}$ in the first phase to 29ppm in the second. This is consistent with the findings of Ayansina and Oso (2006); and has been associated with poorer fertility.

\section{CONCLUSION}

The application of herbicides for weed control, up to their recommended doses resulted in improvement in the growth and yield parameters of the cultivated maize crop. There were however some decreases in these parameters in the second phase, pointing to a possible lingering adverse effects of the herbicides. Efforts are therefore needed to educate farmers on the proper use of the herbicides in reducing the drudgery of farm work, and in increasing crop yield.

Table 1: Physico-chemical characteristics of the soil

\begin{tabular}{lcccc}
\hline Characteristics & $\begin{array}{c}\text { Phase 1 } \\
\mathbf{0 - 1 5} \mathbf{c m}\end{array}$ & Phase 2 & $\begin{array}{c}\text { Phase 1 } \\
\mathbf{1 5 - 3 0 c m}\end{array}$ & Phase 2 \\
\hline Sand (\%) & 58 & 60 & 54 & 56 \\
Clay (\%) & 13 & 13 & 17 & 17 \\
Electrical conductivity 1:2:5 & 0.32 & 0.13 & 0.23 & 0.07 \\
(mS/Cm/25oC) & & & & \\
Soil reaction 1:2:5 (PH) & 4.6 & 3.9 & 4.7 & 4.1 \\
Organic Matter (\%) & 3.2 & 2.2 & 2.5 & 1.4 \\
Total nitrogen (\%) & 0.16 & 0.11 & 0.13 & 0.08 \\
Available phosphorous (ppm) & 48 & 29 & 34 & 22 \\
Exchangeable calcium (ppm) & 167 & 152 & 172 & 109 \\
Exchangeable magnesium (ppm) & 34 & 22 & 27 & 13 \\
Exchangeable potassium (ppm) & 85 & 47 & 71 & 35 \\
Exchangeable sodium (ppm) & 48 & 40 & 48 & 2 \\
\hline
\end{tabular}


Table 2: Mean Germination count of the sown maize seeds one week after planting (1WAP)

\begin{tabular}{llll}
\hline TREATMENT & 2013 (per hectare) & 2014 (per hectare) & P-value \\
\hline 0.53ai/ha & 37,889 & 34,778 & \\
$\mathbf{1 . 0 6 a i} /$ ha & 41,444 & 33,556 & 0.01 \\
$\mathbf{2 . 1 1 a i} /$ ha & 43,889 & 38,809 & \\
$\mathbf{3 . 1 7 a i} /$ ha & 29,889 & 18,748 & \\
$\mathbf{4 . 2 2 a i} /$ ha & 23,333 & 17,111 & \\
Control & 41,667 & 37,333 & \\
P-value & $<0.01$ & $<0.01$ & \\
\hline
\end{tabular}

Table 3: Growth parameters of sown maize

\begin{tabular}{|c|c|c|c|c|c|c|}
\hline \multicolumn{3}{|c|}{ Mean height of maize $(\mathrm{cm})$} & Leaf Count (4WAP) & $\begin{array}{l}2014 \\
\text { (AP) }\end{array}$ & \multicolumn{2}{|c|}{ Mean stand at harvest/hectare } \\
\hline $0.53 \mathrm{ai} / \mathrm{ha}$ & 74.78 & 59.44 & 7.33 & 5.00 & 40,000 & 26.667 \\
\hline $1.06 \mathrm{ai} / \mathrm{ha}$ & 88.72 & 63.56 & 8.00 & 5.39 & 36,667 & 20,556 \\
\hline 2.11ai/ha & 95.17 & 74.39 & 8.16 & 5.50 & 38,889 & 23,444 \\
\hline 3.17ai/ha & 61.44 & 51.94 & 6.10 & 4.63 & 20,000 & 15,111 \\
\hline 4.22ai/ha & 55.83 & 48.17 & 5.50 & 4.22 & 16.667 & 9,000 \\
\hline Control & 79.72 & 64.50 & 8.77 & 5.06 & 37,778 & 26,111 \\
\hline P-value & $<0.05$ & $<0.05$ & $>0.05$ & $>0.05$ & $<0.05$ & $<0.05$ \\
\hline
\end{tabular}

Table 4: Yield parameters of the maize planted in the experimental plots

\begin{tabular}{|c|c|c|c|c|c|c|}
\hline TREATMEN & 2013 & 2014 & 2013 & 2014 & 2013 & 2014 \\
\hline & \multicolumn{2}{|c|}{ No. of harvested cobs/hect } & \multicolumn{2}{|c|}{ Mean field wt. of cobs ( $g / h e c t)$} & \multicolumn{2}{|c|}{ Mean stover weight (g) } \\
\hline $0.53 a i / h a$ & 31,778 & 19,333 & 4,222 & 2,104 & 4,510 & 1,793 \\
\hline 1.06ai/ha & 31,222 & 19,473 & 4,321 & 2,267 & 4,267 & 1,556 \\
\hline 2.11ai/ha & 33,667 & 21,444 & 4,582 & 2,940 & 4,786 & 1,875 \\
\hline 3.17ai/ha & 20,000 & 10,778 & 3,167 & 1,599 & 2,155 & 930 \\
\hline 4.22ai/ha & 16,667 & 8,556 & 2,122 & 1,016 & 1,457 & 889 \\
\hline Control & 37,778 & 26,667 & 4,556 & 2,842 & 4,333 & 1,518 \\
\hline P-value & $<0.05$ & $<0.05$ & $<0.05$ & $<0.05$ & $<0.05$ & $<0.05$ \\
\hline
\end{tabular}

\section{REFERENCES}

1. Adigun JA (2001). Control of weeds with preemergence herbicides in maize- pepper mixture in the Nigerian northern Guinea Savanna: J. Sustainable Agri. Environ. 3: 378-383.

2. Agahiu AE, Baiyeri KP, Ogbuji RO, Udensi UE (2012). Assessment of status, perception of weed infestation and methods of weed control adopted by cassava farmers in Kogi state, Nigeria. Journal of Animal and Plant Sciences 13 (3): 1823 - 1830.

3. Agahiu AE, Udensi UE, Tarawali G, Okoye BC, Ogbuji RO, Baiyeri KP (2011). Assessment of weed management strategies and intercrop combinations on cassava yield in the middle belt of Nigeria. African Journal of Agricultural Research. 6 (26): 5729 - 5735.

4. Ahmed SE, Shams HM, El-Metwally IM, Shehata MN, and El-Wakeel MA, (2008). Efficiency of some weed control treatments on growth, yield and its attributes of maize (Zea mays L.) plants and associated weeds. J. Agric. Sci. Mansoura Univ., 33(7): 4777-4789.
5. Ayansina AD, Oso BA. (2006). Effect of two commonly used herbicide on soil microflora at two different concentrations. Afr. J. Biotech., 5(2): 129-132.

6. Baghestani MA, Zand E, Rahimian Mashhadi $\mathrm{H}$, and Soufizadeh S (2005). Morphological and physiological characteristics which enhance competitiveness of winter wheat (Triticum aestivum) against Goldbachia laevigata. Iranian $J$ Weed Sci I:11126.

7. Cao P, Wang X, Liu F, Zhao E, Han L (2008). Dissipation and Residue of S-metolachlor in Maize and Soil. Bull Environ Contam Toxicol 80: 391 - 394.

8. Ding D, Novak JM, Herbert S, Xing B (2002). Long-term tillage effects on soil metolachlor sorption and desorption behavior. Chemosphere 48: 897 - 904.

9. $\quad$ Eme OI, Onyishi T, Uche OA. Uche IB (2014). Challenges of food security in Nigeria: options before government. Arabian Journal of Business and Management Review (OMAN Chapter). 4 (1): $15-25$.

10. Enyong JK, Ndaeyo NU, Ndon BA, Ugbe LA, Akpan EA (2013). Preliminary evaluation of effects of herbicide types and rates on growth and yield of cassava 
(Manihot esculenta Crantz). International Journal of Basic and Applied Sciences 2 (2): 65 - 70.

11. Franz JE, Sikorski JA, Mao MK (1997). Glyphosate: a unique global herbicide. American Chemical Society. Wasington, DC.

12. Hamid AA, Aiyelaagbe OO, Balogun GA (2011). Herbicides and its Applications. Advances in Natural and Applied Sciences, 5(2): $201-213$.

13. Hawaldar S, Agasimani CA (2012). Effect of herbicides on weed control and productivity of maize (Zea mays L.). Karnataka J. Agric. Sci.,25 (1): 137 139.

14. lyagba AG (2013). Assessing the safety use of herbicides by horticultural farmers in Rivers state, Nigeria. European Scientific Journal 9 (15): 97 - 108.

15. Khan M, Noor-ul-Haq (2004). Weed control in maize with pre-emergence and post-emergence herbicides. Pak. J. of Weed Sci. Res.,.10: 39-46.

16. Khan MS, Zaidi A, Rizvi PQ (2006). Biotoxic effects of herbicides on growth, nodulation, nitrogenase activity, and seed production in chickpeas. Commun. Soil Sci. Plant Anal. 37:1783-1793.

17. Krzysko-Lupicka, T., W. Strof, K. Kubs, M. Skorupa, P. Wieczorek and B. Lejczak. 1997. The ability of soil-borne fungi to degrade organophosphonate carbon-to-phosphorus bonds. Appl. Microbiol. Biotechnol. 48:549-552.

18. Liu SY, Freyer AJ, Bollag JM. (1991). Microbial Dechlorination of the Herbicide Metolachlor. Jour. Agric. Food Chem., 39 (3): 631-636.

19. Liu, C., McClean P, Sookdeo C, Cannon F. (1991). Degradation of the herbicide glyphosate by members of the family rhizobiaceae. Appl. Environ. Microbiol. 57:1799-1804.

20. Munier Lamy C, Feuvrier MP, Chone T (2002). Degradation of 14CAtrazine Bound Residues in Brown soil and Rendzinz Fractions. J. Environ. Qual.31:241247

21. Myers JP, Antoniou MN, Blumberg B, Carroll L, Colborn T, Everett LG, Hansen M, Landrigan PJ, 31.
Lanphear BP, Mesnage R, Vandenberg LN, vom Saal FS, Welshons WV, Benbrook CM (2016). Concerns over use of glyphosate-based herbicides and risks associated with exposures: a consensus statement. Environmental Health. 15:19.

22. Neumann G, Kohls S, Landsberg E, Souza K, Yamada T, Roemheld V. (2006). Relevance of glyphosate transfer to non-target plants via the rhizosphere. Journal of Plant Diseases and Protection Sp. 20: $963-969$.

23. Ojo EO, Adebayo PF (2012). Food security in Nigeria: An overview. European Journal of Sustainable Development 1(2): $199-222$.

24. Racchi ML, Rebecchi M, Todesco G, Nielsen E, Forlani G (1995). Glyphosate tolerance in maize (Zea mays L.). 2. Selection and characterization of a tolerant somaclone. Euphytica 82: 165 - 173.

25. Sergiev IG, Alexieva VS, Ivanov SV, Moskova II, Karanov EN (2006). The phenylurea cytokinin 4PU-30 protects maize plants against glyphosate action. Pesticide Biochemistry and Physiology 85: 139 - 146.

26. Sprankle P, Meggitt W, Penner D (1975a). Adsorption, mobility, and microbial degradation of glyphosate in soil Weed Sci. 23: $229-234$.

27. Tijani AA. (2006). Pesticides Use Practices and Safety Issues: The Case of Cocoa Farmers in Ondo State, Nigeria. J. Human Ecol., 19(3): 183-190.

28. Toloraya, T.R., Malakanova VP, Akhtyrtsev MG (2001). Effectiveness of dates, methods and dozes of applying Zinc Sulphate and its combination with the selective herbicides (Titus) in maize sowings. KukuruzaISerge. No.2:5-7. (CAB Absts., 2001.

29. van Heemst HD (1985). The influence of weed competition on crop yield. Agricultural Systems. 18 (2):81-93.

30. Yazdanpak A, Amiri A, Faghihi K, Karimian NA (2014). The residual effect of herbicides on the germination and early growth of shiraz wheat cultivar in the development of healthy agricultural crops. AmericanEurasian J. Agric. \& Environ. Sci., 14 (2): 161 - 164. 